\title{
Preparation and Application of Tetracycline Hydrochloride Liquid membrane Electrodes.
}

\author{
Amina M. Abass \\ Department of Chemistry, College of Sciences, Al-Nahrain University, Al-Jaderia, Baghdad-Iraq. \\ Corresponding Author: aminamohsen75@gmail. com.
}

\begin{abstract}
Two liquid membrane electrodes for $(\mathrm{TCH})$ were prepared by using ion pair which included phosphomolybdic acid (PMA)-(TCH) with plasticizers: Di-n-butyl phthalate(DBPH), and dioctylphenylphosphonate (DOPH). Tetracycline electrodes were gave a Nernstain response equal to 56. 51 and 50. $66 \mathrm{mV} /$ decade for membranes depended on DBPH and DOPH as a plastisizers, respectively. Linear ranges were around 6. $8 \times 10^{-6}-1.0 \times 10^{-1}$ and $1.0 \times 10^{-5}-1.0 \times 10^{-1} \mathrm{M}$, respectively. Detection limit were equal to $4.0 \times 10^{-6}, 5.0 \times 10^{-6} \mathrm{M}$, respectively. $\mathrm{PH}$ range were also studied at three different concentration of tetracycline solutions. As well as were studied lifetime, selectivity, potentiometric methods such as direct, standard addition , multiple standard addition and titration methods were applied to determination tetracycline in pharmaceutical preparation.
\end{abstract}

[DOI: $10.22401 / \mathrm{JNUS} .21 .2 .11]$

Keywords: determination of tetracycline, PVC electrodes, Sensors, phosphomolybdic acid.

\section{Introduction}

Tetracycline hydrochloride are extensively used for control and inhibition of disease[1]. It founded as yellow, crystalline powder, insoluble in acetone and slightly soluble in ethanol, soluble in water. Molecular weight equal to $480 \mathrm{gm}$. mole $\mathrm{e}^{-1}$. Fig.(1) shown the structure of TCH. It's used as antibacterial[2].<smiles>CN(C)[C@H]1C(O)=C(C(N)=O)C(=O)[C@]2(O)C(O)=C3C(=O)c4c(O)cccc4[C@@](C)(O)[C@H]3C[C@H]12</smiles>

Fig.(1): Structure of Tetracycline hydrochloride.

Different chemical techniques were used for determination $\mathrm{TCH}$, one of these was liquid chromatography with spectrofluoreometric for determination of tetracycline [3]. High performance liquid chromatographic [4]. Sensitive spectrophotometer [5]. New method depended on voltammetry for evaluated tetracycline in probes of honey [6]. Colorimetric method was used to determination tetracycline in acidic and alkaline solutions [7]. Founded tetracycline in honey samples by used multianalyte/multiclass ultra-performance liquid chromatography-tandem mass spectrometry (UPLC-MS/MS) [8]. Ion selective electrodes used widely in pharmaceutical analysis because these electrodes suggestion the benefits of simple model working, responsible selectivity, stable response, little cost and applicability to colored and turbid solutions. In this research membranes were based on phosphomolybdic acid as additive in poly vinyl chloride matrix with different plasticizers were used for the determination of $\mathrm{TCH}$ in pharmaceutical preparation.

\section{Experimental}

\section{Chemicals and Reagents}

1.Phosphomolybdic acid (PMA) was obtained from (BDH).

2.Tetrahydrofuran (THF) was supplied from (BDH).

3.Tetracycline hydrochloride (TCH) was provided from (Samara, IRAQ-SDI) Drug Industries and State Company and Medical Appliance.

4.Tetracycline (500 mg) Capsules, were from India.

5.Plasticizers: Di-n-butyl phthalate (DBPH), Di-octylphenylphosphonate (DOPH) were equipped from Fluka AG.

6.PVC chemical was supplied from U. K. Ltd, type: Breon S110/10 B. P.

7.From stockpile solutions which concentration $0.1 \mathrm{M}$ were prepared of 
$\mathrm{AlCl}_{3}, \mathrm{FeCl}_{3}, \mathrm{CaCl}_{2}, \mathrm{MgCl}_{2}, \mathrm{KCl}$, and $\mathrm{LiCl}$, complementary diluted solutions prepared by succeeding dilution of the solution.

8. From Fluka, Aldrich and BDH, all chemicals materials of analytical were supplied.

\section{Equipments}

1.WTW model PH720, Germany, ${ }_{\mathrm{P}} \mathrm{H}$ meter.

2.An expandable ion analyzer(WTW)model, Germany.

3.Saturated electrode of Calomel type: Gallenkamp, USA.

\section{Potentiometric techniques}

Standard addition method(SAM) was applied to determination $\mathrm{TCH}$ in samples: standard (pure form) and pharmaceutical preparation by calculated the concentration of tetracycline hydrochloride followed equation: $[9,10]$

$$
\mathrm{CU}=\mathrm{CS} / 10^{\Delta \mathrm{E} / \mathrm{S}}[1+(\mathrm{VU} / \mathrm{VS})]-(\mathrm{VU} / \mathrm{VS})
$$

Where $\mathrm{C}_{\mathrm{U}}, \mathrm{C}_{\mathrm{S}}, \mathrm{V}_{\mathrm{U}}$ and $\mathrm{V}_{\mathrm{S}}$ are the concentration and volume of unknown and standard solution, respectively, Also multiple standard addition method(MSA) was applied. In this method, several addition of standard solution to the same sample to be measured in order to increase the accuracy and decreases the errors by followed equation:

Antilog $\mathrm{E} / \mathrm{S}=$ constant $\times \mathrm{a}_{\mathrm{x}} \mathrm{V}_{\mathrm{S}} / \mathrm{V}_{\mathrm{U}}$.

Where antilog(E/S) is constant, thus the $\operatorname{antilog}(E / S)$ is proportional to $V_{S}$. A plot of $\operatorname{antilog}(E / S)$ against $V_{S}$, the linear straight was depended, the intercept of which with the volume axis refer to the end point of unidentified concentration in an adding method.

\section{Properties of PVC and Plasticizers}

Poly (Vinyl Chloride), PVC is an amorphous, brittle thermoplastic that is easily mixed with various additives to obtain a broad variety of material properties. It' $s$ wide range of physical, chemical, and mechanical properties. It' $\mathrm{s}$ durability, and its cost effectiveness make PVC useful in applications. Plasticizer is a major component of the tetracycline - selective electrode, which results in excellent mobility of free and complexed ionophores mechanical property and adjusted dielectric constant. In this work, two plasticizers were used to evaluate their effects on the slopes may be is the less lipophility and therefore greater polarity of the DBPH and DOPH that makes it a better case for the tetracycline-selective membrane electrodes [11].

\section{Results and Treatment}

The electrochemical performance characteristics of the membrane was evaluated according to IUPAC recommendation and the results are summarized in and Schema (1). and Table (1). The first electrode based on DBPH was have high value of slope equal to56. 51 $\mathrm{mV}$ per decade thus, because the high mixing between the DBPH and PVC due to the compatibility of the plasticizer used to the electro active compound in both structure and composition [12]. The linear range was near to 6. $8 \times 10^{-6}-1.0 \times 10^{-1} \mathrm{M}$, with detection limit around $4.0 \times 10^{-6} \mathrm{M}$. Correlation coefficient was equal to 0.9995 , while the electrode depended on DOPH was gave Nernstain response from $1.0 \times 10^{-5}$ to $1.0 \times 10^{-1} \mathrm{M}$, and calibration slope of $50.66 \mathrm{mV} /$ decade, with lower limit of detection of $5.0 \times 10^{-6} \mathrm{M}$, and Correlation coefficient near to 0.9994. Lifetime were 35 and 30 day for first and second electrodes, respectively.

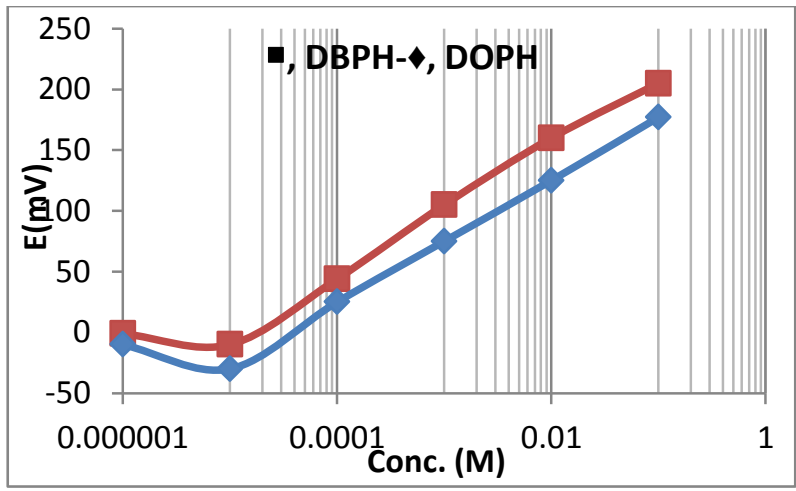

Schema(1): Calibration graph of tetracycline hydrochloride electrodes. 
Table (1)

Response of tetracycline hydrochloride electrodes(TCH-PMA).

\begin{tabular}{|c|c|c|}
\hline Type. of membrane & $\begin{array}{c}T C H+D B P H+P M A \\
\text { (1) }\end{array}$ & $\begin{array}{c}T C H+D O P H+P M A \\
\text { (2) }\end{array}$ \\
\hline Concentration range(M) & $6.8 \times 10^{-6}-1.0 \times 10^{-1}$ & $1.0 \times 10^{-5}-1.0 \times 10^{-1}$ \\
\hline $\begin{array}{c}\text { Correlation coefficient } \\
(R)\end{array}$ & 0.9995 & 0.9994 \\
\hline Detection limit(M) & $4.0 \times 10^{-6}$ & $5.0 \times 10^{-6}$ \\
\hline Slope (mV/decade) & 56.51 & 50.66 \\
\hline $\begin{array}{l}\text { Regre. Eq. } \\
Y=m X+b\end{array}$ & $Y=24.538 \ln (x)+274$ & $Y=22.366 \ln (x)+229$ \\
\hline Lifetime (day) & 35 & 30 \\
\hline
\end{tabular}

\section{Response time}

The response time of the new $\mathrm{TCH}$ electrode was measured by immersing the assembly in a series of different TCH solutions in which the concentration of the drug increase tenfold [13].The response time of the electrode which is the time required to reach $95 \%$ of its final potential was determined. Response time was decreases with increases the concentration of TCH it was somewhere(5.0-10.0) second. Values of response time recorded in Table (2).

Table (2)

Response Time of TCH electrodes.

\begin{tabular}{|c||c||c||}
\hline $\begin{array}{c}\text { TCH } \\
\text { Conc.(M) }\end{array}$ & \multicolumn{2}{c|}{ Response time(Sec) } \\
\hline \hline & $\begin{array}{c}\text { Electrode } \\
\text { (TCH+DBPH+PMA) }\end{array}$ & $\begin{array}{c}\text { Electrode } \\
\text { (TCH+DOPH+PMA) }\end{array}$ \\
\hline \hline $\mathbf{1 0}^{-1}$ & 5.0 & 5.0 \\
\hline $\mathbf{1 0}^{-2}$ & 6.5 & 6.8 \\
\hline \hline $\mathbf{1 0}^{-3}$ & 7.8 & 7.5 \\
\hline \hline $\mathbf{1 0}^{-4}$ & 8.0 & 9.0 \\
\hline \hline $\mathbf{1 0}^{-5}$ & 9.0 & 10.0 \\
\hline
\end{tabular}

\section{Effect of PH}

A study of the potential response of $(\mathrm{TCH}-$ PVC-PMA) membrane' $\mathrm{S}$ electrode as a function of change in the $\mathrm{PH}$ of the drug[14].The range of $\mathrm{PH}$ at concentration $10^{-2} \mathrm{M}$ were 2.0-7.0, 3.5-5.6 for electrodes $\mathrm{DBPH}$, DOPH, respectively, and for concentration $10^{-3} \mathrm{M}$, ranges of $\mathrm{PH}$ were 3.5- 7.5, 4.0-7.3, respectively, and with concentration $10^{-4} \mathrm{M}$, the $\mathrm{PH}$ range were 4.0 7.5, 3.5-6.0, respectively. schema (2) shown the working $\mathrm{PH}$ for electrode depended on $\mathrm{BBPH}$ as a plasticizer and Table (3) listed the range of $\mathrm{PH}$ for $\mathrm{TCH}$ electrodes.

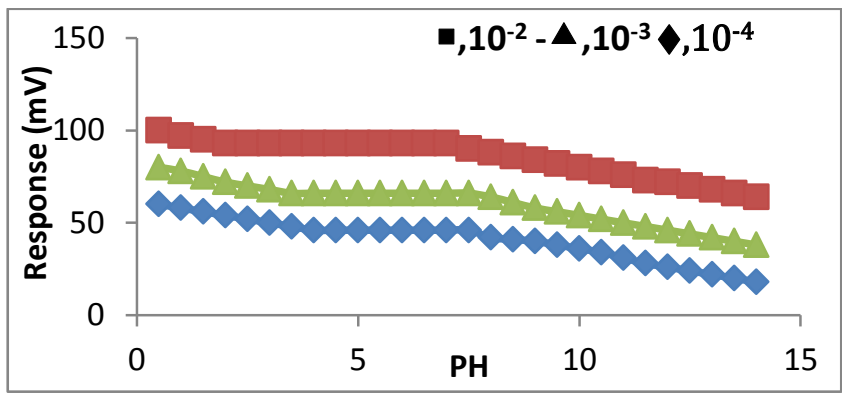

Schema (2): Working range ${ }_{P} H$ for $\mathrm{TCH}$ solutions at different concentration using $(\mathrm{TCH}+\mathrm{DBPH}+\mathrm{PMA})$ electrodes.

Table (3)

Range of ${ }_{P} H$ for $(T C H+D B P H+M P A)$ electrode.

\begin{tabular}{|c||c||c|c|c||}
\hline \multirow{2}{*}{ Number } & \multicolumn{1}{c||}{$\begin{array}{c}\text { Membrane } \\
\text { composition }\end{array}$} & \multicolumn{3}{c|}{$p H$ range } \\
\cline { 3 - 5 } & \multirow{2}{*}{ } & $\mathbf{1 0}^{-2}$ & $\mathbf{1 0}^{-3}$ & $\mathbf{1 0}^{-4}$ \\
\hline \hline \multirow{2}{*}{$\mathbf{1}$} & \multirow{2}{*}{$T C H+D B P H+M P A$} & $2.0-$ & $3.5-$ & $4.0-$ \\
& \multirow{2}{*}{$T .0$} & 7.5 & 7.5 \\
\hline \multirow{2}{*}{$\mathbf{2}$} & \multirow{2}{*}{$T C H+D O P H+M P A$} & $3.5-$ & $4.0-$ & $3.5-$ \\
& 5.6 & 7.3 & 6.0 \\
\hline
\end{tabular}

\section{Calculation of Selectivity coefficient}

The selectivity is one of the most important characteristics of an electrode, as it often determines whether a reliable measurement in the sample is possible or not. The IUPAC suggests two methods: separate solution method (SSM) and fixed interference method (FIM). There is also an alternative method of the selectivity determination called matched potential method (MPM). Each of them has got advantages and drawbacks, and there are not general rules pointing which method gives the true result. The methods proposed by IUPAC with several precautions will give meaningful data. Selectivity coefficient were calculated and recorded in Table (4) and Table (5) for electrodes (TCH+DBPH+PMA), (TCH+DOPH+PMA), 
respectively, and Schema (3), (4) shown the interferings ions with $\mathrm{TCH}$ using electrodes ( $\mathrm{TCH}+\mathrm{DBPH}+\mathrm{PMA}), \quad(\mathrm{TCH}+\mathrm{DOPH}+\mathrm{PMA})$, respectively. From these results showed that the values of selectivity coefficient was increased when the concentration of the drug decrease [15], and there is no interfering ions with drug $\mathrm{TCH}$.

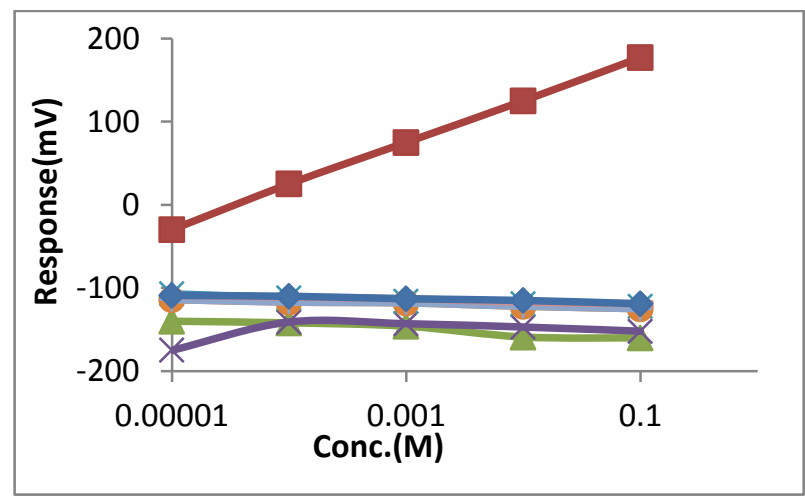

Schema (3): Selectivity of electrode (1) $(\mathrm{TCH}+\mathrm{DBPH}+\mathrm{MPA})$ for interferings $\mathrm{TCH}, \diamond \mathrm{Al}^{3+}, \triangle \mathrm{Fe}^{+3}, \mathrm{Mg}^{2+}, \times \mathrm{Ca}^{2+}, \nabla \mathrm{K}^{1+}, * \mathrm{Li}^{1+}$

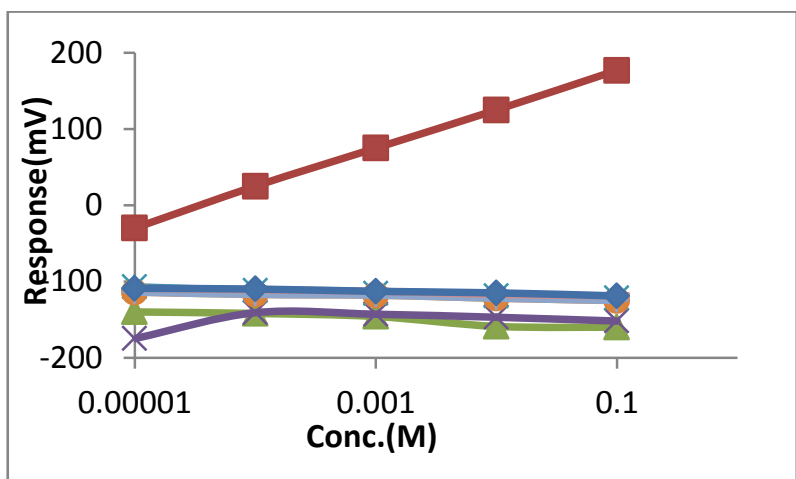

Schema (4): Selectivity of electrode (2) $(\mathrm{TCH}+\mathrm{DOPH}+\mathrm{MPA})$ for interferings $\mathrm{TCH}, \diamond \mathrm{Al}^{3+}, \triangle \mathrm{Fe}^{+3}, \bullet \mathrm{Mg}^{2+}, \times \mathrm{Ca}^{2+}, \mathrm{IK}^{\mathrm{I+}^{+}}, * \mathrm{Li}^{1+}$

Table (3)

Slectivity coefficients calculated for electrode $1(T C H+D B P H+M P A)$.

\begin{tabular}{|c|c|c|c|c|c|}
\hline \multicolumn{6}{|c|}{ Electrode 1 (TCH+DBPH+MPA) } \\
\hline \multicolumn{6}{|c|}{ Concentration of Tetracycline hydrochloride } \\
\hline Ion & $10^{-5}$ & $10^{-4}$ & $10^{-3}$ & $10^{-2}$ & $10^{-1}$ \\
\hline $\mathbf{L i}^{1+}$ & $8.6700 \times 10^{-2}$ & $3.2600 \times 10^{-2}$ & $2.2161 \times 10^{-3}$ & $1.4453 \times 10^{-4}$ & $2.2179 \times 10^{-5}$ \\
\hline $\mathbf{K}^{1+}$ & $7.6700 \times 10^{-2}$ & $2.8800 \times 10^{-2}$ & $2.1276 \times 10^{-3}$ & $1.8456 \times 10^{-4}$ & $1.8843 \times 10^{-5}$ \\
\hline $\mathrm{Ca}^{2+}$ & $1.3998 \times 10^{-3}$ & $9.4109 \times 10^{-4}$ & $2.1056 \times 10^{-4}$ & $6.5271 \times 10^{-5}$ & $3.1674 \times 10^{-5}$ \\
\hline$\overline{\mathbf{M g}^{2+}}$ & $1.1418 \times 10^{-3}$ & $9.0351 \times 10^{-4}$ & $7.3758 \times 10^{-5}$ & $6.7985 \times 10^{-5}$ & $3.0409 \times 10^{-5}$ \\
\hline $\mathrm{Fe}^{3+}$ & $1.2610 \times 10^{-4}$ & $2.4011 \times 10^{-4}$ & $8.5422 \times 10^{-5}$ & $3.5769 \times 10^{-5}$ & $2.4422 \times 10^{-5}$ \\
\hline$\overline{\mathbf{A l}^{3+}}$ & $1.2106 \times 10^{-4}$ & $2.5009 \times 10^{-4}$ & $8.8974 \times 10^{-5}$ & $4.0419 \times 10^{-5}$ & $2.7598 \times 10^{-5}$ \\
\hline
\end{tabular}

Table (4)

Slectivity coefficients calculated for electrode $2(T C H+D O P H+M P A)$.

\begin{tabular}{|c|c|c|c|c|c||}
\hline \multicolumn{7}{||c||}{ Electrode 2 (TCH+DOPH+PMA) } \\
\hline \multicolumn{7}{|c|}{ Concentration of Tetracycline hydrochloride } \\
\hline \hline Ion & $\mathbf{1 0}^{-5}$ & $\mathbf{1 0}^{-4}$ & $\mathbf{1 0}^{-3}$ & $\mathbf{1 0}^{-2}$ & $\mathbf{1 0}^{-1}$ \\
\hline \hline $\mathbf{L i}^{\mathbf{1 +}}$ & $6.7400 \times 10^{-3}$ & $5.0525 \times 10^{-4}$ & $4.3409 \times 10^{-5}$ & $2.4774 \times 10^{-6}$ & $2.2274 \times 10^{-7}$ \\
\hline \hline $\mathbf{K}^{\mathbf{1 +}}$ & $1.3733 \times 10^{-3}$ & $5.2875 \times 10^{-4}$ & $4.9751 \times 10^{-4}$ & $4.2743 \times 10^{-6}$ & $3.2042 \times 10^{-7}$ \\
\hline \hline $\mathbf{C a}^{2+}$ & $9.5513 \times 10^{-5}$ & $1.9755 \times 10^{-5}$ & $5.3674 \times 10^{-6}$ & $1.5260 \times 10^{-6}$ & $3.9619 \times 10^{-7}$ \\
\hline $\mathbf{M g}^{2+}$ & $6.9484 \times 10^{-5}$ & $1.5739 \times 10^{-5}$ & $4.9010 \times 10^{-6}$ & $1.3315 \times 10^{-6}$ & $3.4569 \times 10^{-7}$ \\
\hline $\mathbf{F e}^{3+}$ & $1.2752 \times 10^{-5}$ & $4.4405 \times 10^{-6}$ & $1.9542 \times 10^{-6}$ & $7.7813 \times 10^{-7}$ & $3.0983 \times 10^{-7}$ \\
\hline \hline $\mathbf{A l}^{3+}$ & $1.2899 \times 10^{-5}$ & $4.6900 \times 10^{-6}$ & $1.9542 \times 10^{-6}$ & $8.5218 \times 10^{-7}$ & $3.0983 \times 10^{-7}$ \\
\hline \hline
\end{tabular}


Analysis of tetracycline hydrochloride Samples

The accuracy of electrodes 1 and 2 were measured by determining $\mathrm{TCH}$ standard and synthetic solutions of $10^{-3}$ and $10^{-4} \mathrm{M}$, using direct, standard addition, multiple standard addition and, titration methods. Excellent results of \% recovery were listed in Table (6), (7) and a typical plot for electrode 1 and 2 at concentration of solutions $10^{-3}, 10^{-4} \mathrm{M}$ is shown in schema 5, 6,7,8,9,10, with schema 11 for titration $10^{-3} \mathrm{M}$ of $\mathrm{TCH}$ vs. phosphomolybdic acid as a titrant, which was have a concentration of $10^{-3} \mathrm{M}$.

Table (6)

Potentiometric techniques for analysis of TCH samples.

\begin{tabular}{|c|c|c|c|c|c|}
\hline \multirow{3}{*}{ Electrode Type } & \multicolumn{5}{|c|}{ Concentration(M) } \\
\hline & \multirow{2}{*}{ Sample } & \multicolumn{4}{|c|}{ Response by potentiometric method } \\
\hline & & Direct & SAM & MSA & Titration \\
\hline \multirow{8}{*}{ TCH+DBPH+PMA } & $1 \times 10^{-3} \mathrm{M}$ & $0.9733 \times 10^{-3}$ & $0.9963 \times 10^{-3}$ & $0.9891 \times 10^{-3}$ & 0.9870 \\
\hline & RSD\% & 0.84 & 0.16 & - & $1-$ \\
\hline & $\operatorname{Re} \%$ & 97.33 & 99.63 & 98.91 & 98.70 \\
\hline & $\mathrm{Er} \%$ & -2.67 & -0.37 & -1.09 & -1.30 \\
\hline & $1 \times 10^{-4} \mathrm{M}$ & $0.9609 \times 10^{-4}$ & $0.9960 \times 10^{-4}$ & $0.9870 \times 10^{-4}$ & $0.9864 \times 10^{-4}$ \\
\hline & RSD\% & 1.27 & 0.24 & - & - \\
\hline & $\operatorname{Re} \%$ & 96.09 & 99.60 & 98.70 & 98.64 \\
\hline & Er\% & -3.91 & -0.40 & -1.30 & -1.36 \\
\hline \multirow{8}{*}{ TCH+DOPH+PMA } & $1 \times 10^{-3} \mathrm{M}$ & $0.9759 \times 10^{-3}$ & $0.99141 \times 10^{-3}$ & $0.9988 \times 10^{-3}$ & $0.9612 \times 10^{-3}$ \\
\hline & RSD\% & 0.41 & $\begin{array}{c}0.33 \\
\end{array}$ & - & - \\
\hline & $\operatorname{Re} \%$ & 97.59 & 99.14 & 99.88 & 96.12 \\
\hline & Er\% & -2.41 & -0.86 & -0.12 & -3.88 \\
\hline & $1 \times 10^{-4} \mathrm{M}$ & $0.9677 \times 10^{-4}$ & $0.9959 \times 10^{-4}$ & $0.9894 \times 10^{-4}$ & $0.9723 \times 10^{-4}$ \\
\hline & RSD\% & 0.76 & 0.67 & - & - \\
\hline & $\operatorname{Re} \%$ & 96.77 & 99.59 & 98.94 & 97.23 \\
\hline & Er\% & -3.23 & -0.41 & -1.06 & -2.77 \\
\hline
\end{tabular}

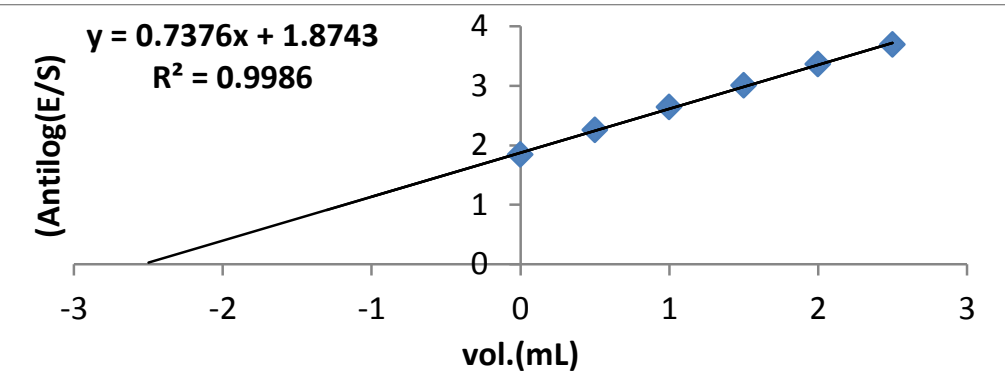

Schema (5): Antilog (E/S)versus volume of $10^{-3} \mathrm{M}$ added of tetracycline using electrode1 (TCH+DBPH+PMA).

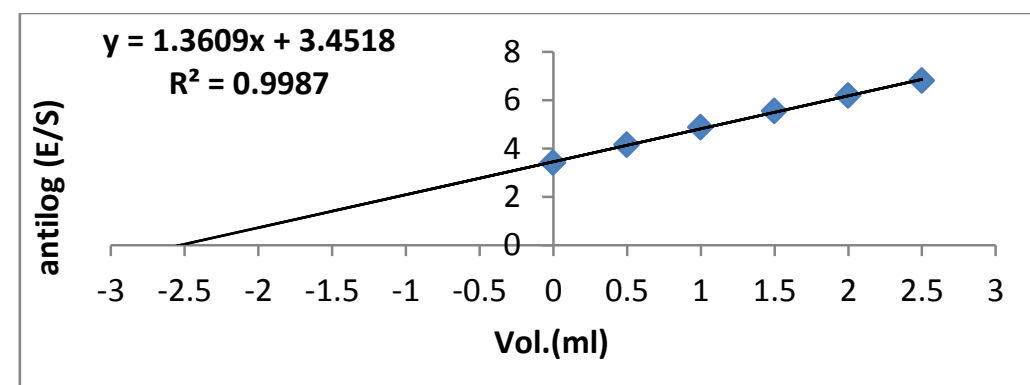

Schema (6): Antilog (E/S)versus volume of $10^{-4} \mathrm{M}$ added of tetracycline using electrode $1(T C H+D B P H+P M A)$. 


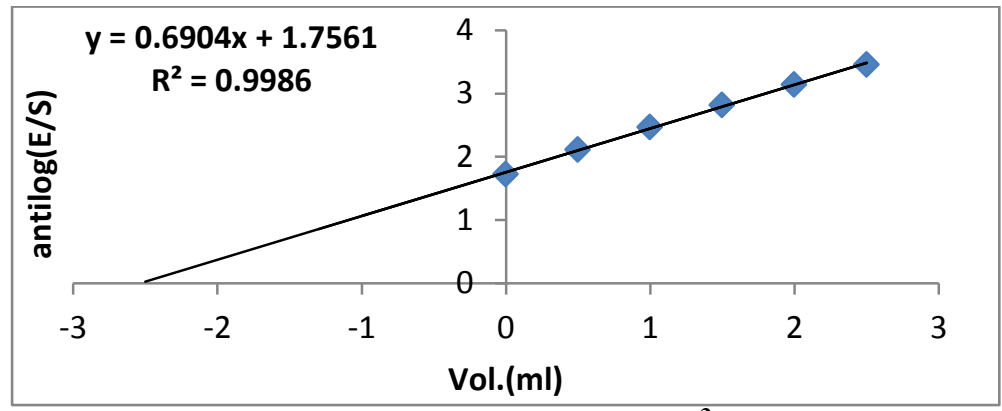

Schema (7): Antilog (E/S)versus volume of $10^{-3} \mathrm{M}$ added of tetracycline using electrode $2(\mathrm{TCH}+\mathrm{DOPH}+\mathrm{PMA})$.

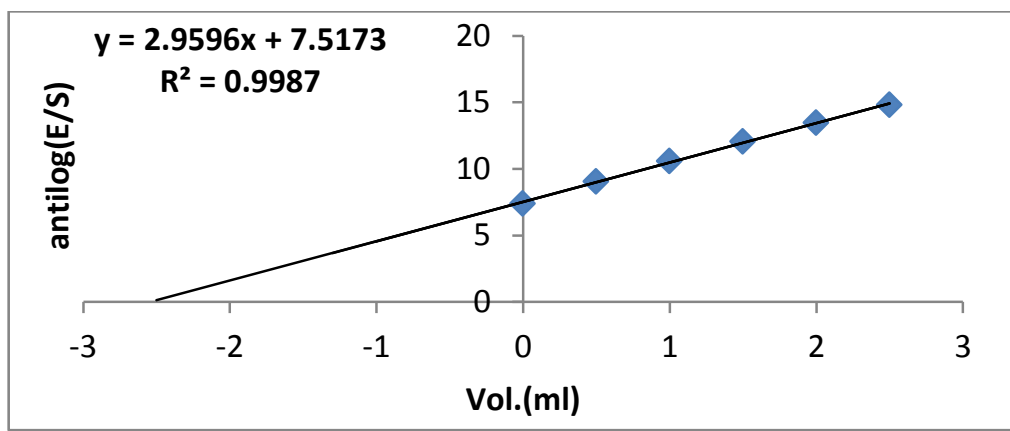

Schema (8): Antilog (E/S)versus volume of $10^{-4} \mathrm{M}$ added of tetracycline using electrode $2(\mathrm{TCH}+\mathrm{DOPH}+\mathrm{PMA})$.

Table (7)

Potentiometric techniques for analysis of TCH capsules.

\begin{tabular}{|c|c|c|c|c|c|}
\hline \multirow{3}{*}{ Electrode Type } & \multicolumn{5}{|c|}{ Concentration(M) } \\
\hline & \multirow{2}{*}{ Sample } & \multicolumn{4}{|c|}{ Response by potentiometric method } \\
\hline & & Direct & SAM & MSA & Titration \\
\hline \multirow{4}{*}{ TCH+ DBPH+PMA } & $1 \times 10^{-3} \mathrm{M}$ & $0.9667 \times 10^{-3}$ & $0.9957 \times 10^{-3}$ & $0.9898 \times 10^{-3}$ & $0.9846 \times 10^{-3}$ \\
\hline & RSD\% & 0.68 & 0.32 & - & - \\
\hline & $\operatorname{Re} \%$ & 96.67 & 99.57 & 98.98 & 98.46 \\
\hline & Er\% & -3.33 & -0.43 & -1.02 & -1.54 \\
\hline \multirow{4}{*}{ TCH+ DOPH+PMA } & $1 \times 10^{-3} \mathrm{M}$ & $0.9846 \times 10^{-3}$ & $0.9856 \times 10^{-3}$ & $0.9895 \times 10^{-3}$ & $0.9751 \times 10^{-3}$ \\
\hline & RSD\% & 0.74 & 0.41 & - & - \\
\hline & $\operatorname{Re} \%$ & 98.46 & 98.56 & 98.95 & 97.51 \\
\hline & Er\% & -1.54 & -1.44 & -1.05 & -2.49 \\
\hline
\end{tabular}

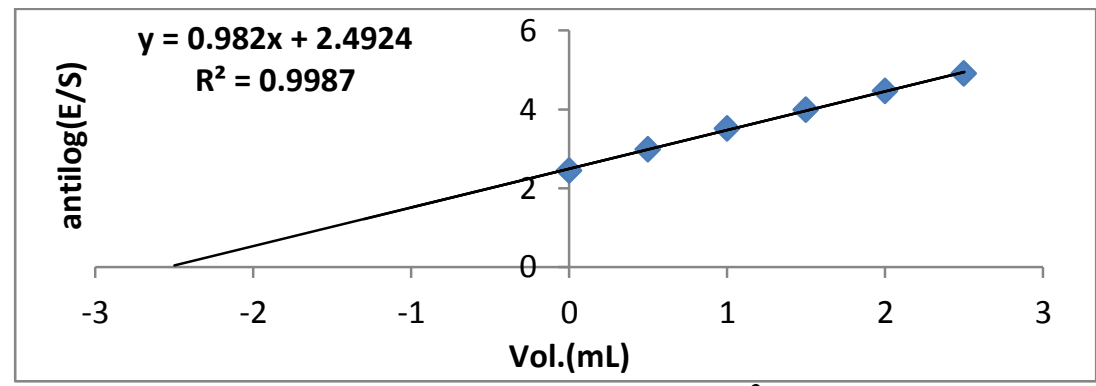

Schema (9): Antilog (E/S)versus volume of $10^{-3} \mathrm{M}$ added of tetracycline using electrode1 $(\mathrm{TCH}+\mathrm{DBPH}+\mathrm{PMA})$. 


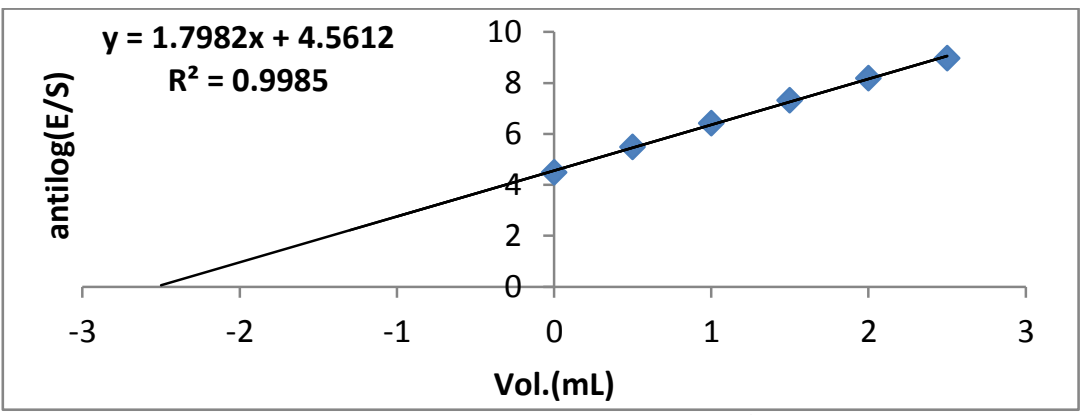

Schema (10): Antilog (E/S)versus volume of $10^{-3} \mathrm{M}$ added of tetracycline using electrode2 (TCH+DOPH+PMA).

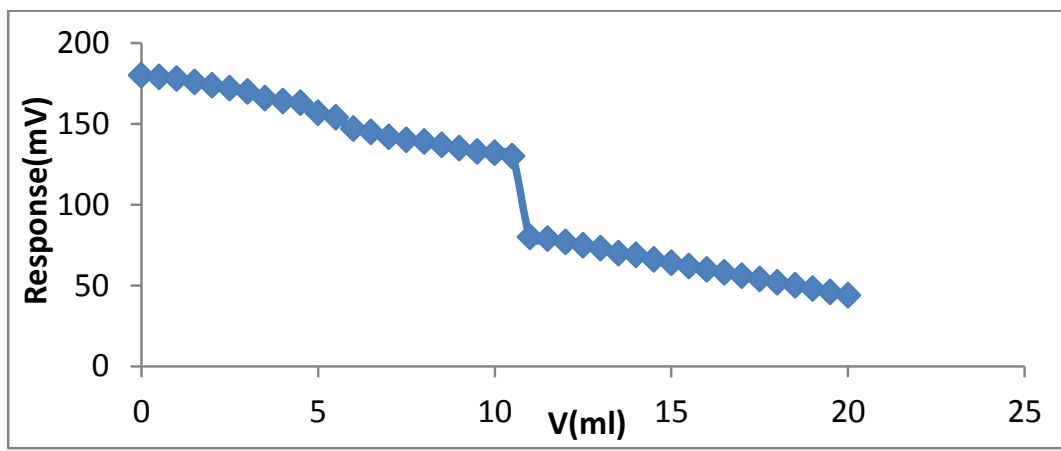

Schema (11): Titration curve for sample $\left(1 \times 10^{-3} \mathrm{M}\right)$ of $\mathrm{TCH}$ with $\left(1 \times 10^{-3} \mathrm{M}\right)$ of MPA standard by electrode $(\mathrm{TCH}+\mathrm{DBPH}+\mathrm{MPA})$.

\section{Conclusion}

Ion Selective Electrodes method included construction of membranes for Tetracycline hydrochloride was fabricated depended on TCH with phosphomolybdic acid (PMA) as chemical addition and two plasticizers. Two best electrodes for determination $\mathrm{TCH}$ with $\mathrm{DBPH}$ and DOPH as a plasticizers and there is no interferences for some interfering ions.

\section{References}

[1] Gaurva A., Gill J.P.S., Aulakh R.S., Bedi J S. "ELISA based monitoring and analysis of tetracycline residues in cattle milk in various districts of Punjab", Veterinaryworld org, 7, 2014.

[2] British pharmacopoeia 2013, Version 17 Copyright by., London, 2012.

[3] Pana A., Lino C.M., Alonso R., Barcelo D.; "Determination of Tetracycline Antibiotic Residues in Edible Swine Tissues by Liquid Chromatography with spectrofluorometric detection and confirmation by Mass spectrometry", J. Agric. Food Chem, 55, 4974-4979, 2007.

[4] Senyuva H., Özden T., Sarica D.Y.; "High -Performance Liquid Chromatographic determination of oxytetracycline Residue in cured meat products" Turk J Chem 24,395400, 2000.

[5] Dhamra M.Y., Al-Sabha T.N., Al-Ghabsha T.S.; "Spectrophotometric determination of Terbutaline Sulphate and tetracycline hydrochloride via ion pair complex formation using Eosin Y", Pak. J. Anal. Environ. Chem., 15(1), 84-92, 2014

[6] Akeneev Y.A., Slepchenko G.B., Deryabina V.I., Maximchuk I.O., Shchukina T.I.; "Determination of Tetracycline in Honey by Voltammetry, Procedia Chemistry", 15, 355-359, 2015.

[7] Ali M.A.M., "Stability Study of Tetracyclinedrug in Acidic and alkaline solutions by Colorimetric Method", Journal of Chemical and Pharmaceutical Research, 4(2), 1319-1326, 2012.

[8] Kivrak I., Kivrak S., Harmandar M.; "Development of a rapid method for the determination of antibiotic residues in Honey using UPLC-ESI-MS/MS", Food Sci. Technol, Compinas, 3(1), 90-96, 2016.

[9] Ammar R.; "A New Ritodrine Selective Electrode and its Pharmaceutical Application", E-Journal of Chemistry, 7(S1), 103-110, 2010. 
[10] Abass A.M., "Synthesis New liquid selective electrodes of ciprofloxacine hydrochloride for determination ciprofloxacin in pure form and pharmaceutical preparations", Baghdad Science Journal, 14(4), 787-792, 2017.

[11] Ghoreishi S.M., Behpour M., Zahrani H.A., Golestaneh M.; "Preparation and Optimization of a Ketotifen Sensor and Its Pharmaceutical Applications", Anal. Bioanal. Electrochem., 2(3):112-124, 2010.

[12] Al-Saidi K.H., Munshid H.Q.; "New Polymeric Membrane Electrode for Clarithromycin Determination, Journal of Al-Nahrain University, 16(2), 30-36, 2013.

[13] Arida H., Al-robaian M., El- M., Fataftah A., Al-Sllami G.; "A New Coated Wire Selective Electrode for Quetiapine in Biological and Pharmaceutical Analysis", Int.J. Electrochem. Sci., 12, 4120- 4133, 2017.

[14] Abass A.M., Ahmed A., "Synthesis and Application of Trimethoprim Selective Electrodes", RJLBPCS, 3(2), 146-156, 2017.

[15] Abass A.M., Al-Phalahy B.A.; "Construction and Charactrization of Chloropromazine hydrochloride Selective Electrode Based on Complex Chloropromazine hydrochloride -Sodium tetra phenyl borate on a PVC Matrix" Tikrit Journal of Pure Science, 17(2), 112-119, 2012. 